\title{
FLOW CHARACTERISTICS IN A MILDLY MEANDERING CHANNEL WITH \& WITHOUT RIVER TRAINING STRUCTURES
}

\author{
Sanjay GIRI ${ }^{1}$, Yasuyuki SHIMIZU ${ }^{2}$ and Mutsuhiro FUJITA ${ }^{3}$ \\ ${ }^{1}$ Student member of JSCE, Post-graduate student, Dept. of Hydroscience \& Environmental Engineering, Hokkaido \\ University (Kita 13, Nishi 8, Sapporo 060, Japan) \\ ${ }^{2}$ Member of JSCE, D. Eng., Associate Professor, Dept. of Hydroscience \& Environmental Engineering, Hokkaido \\ University (Kita 13, Nishi 8, Sapporo 060, Japan) \\ ${ }^{3}$ Fellow of JSCE, D. Eng., Professor, Dept. of Hydroscience \& Environmental Engineering, Hokkaido University \\ (Kita 13, Nishi 8, Sapporo 060, Japan)
}

\begin{abstract}
The experimental study reported herein was carried out in a meandering flume with three consecutive bends. The radius-width ratio was 3 and the arc angles of each bend were $40^{\circ}, 80^{\circ}$ and $40^{\circ}$ respectively. The study was performed for various cases of with and without structures. Non-submerged spur dikes were placed as river training structure in concave part of the bend entrance. The flow field without spur dikes, with one, two and three spur dikes was measured under similar flow condition in order to assess the influence of the structures on flow pattern. For the sake of comparability, the velocity field throughout the bend reach has been measured in all cases and depicted in non-dimensional form. Some specific features associated with the flow processes in a mildly meandering channel were observed. Of most notable observation in this study is the existence of a dead region near the outer part of subsequent bend induced by the structures placed in bend entrance.
\end{abstract}

Key Words: mildly meandering channel, river training work, spur dikes, recirculation region, shear layer, critical distance.

\section{INTRODUCTION}

Several experimental and numerical studies on flow and bed variation around river training structures like spur dike have been performed and still being carried out. The performance of these structures and their effect on riverbed evolution is of great importance from practical engineering point of view. According as several field investigations, their performance is often found to be quite unpredictable despite numerous studies and proposed design criteria for river training works.

Most of the previous studies on flow behavior around such structure were carried out for the case of straight flume and with a single spur dike ${ }^{1)}$. Some studies were performed upon movable bed condition considering mean flow properties to observe local scour near structure ${ }^{2), 3}$. One of the recent works of Fukuoka et al. ${ }^{4)}$ comprises the counter measures against bed variation using groins in Shinano river. Besides, some studies have been carried out to analyze flow structure in groin region ${ }^{5)} \&$ exchange process between groin and main flow region ${ }^{6), 7)}$.

There are some significant numerical studies such as one performed by Muneta \& Shimizu ${ }^{8}$. In this study, a direct numerical calculation of quazi 3D-flow in a straight channel with spur dike was performed in consideration of the secondary flow using Engelund's cross flow equation. Model reproduced the characteristics of secondary flow well except in few cases in the vicinity of spur dike due to the strong 3D-flow around the structure as described by Shimizu.

It is significant to emphasize that river training structures are usually placed in the bend reach of channel. Moreover, they are placed in series so as to achieve better effect from both bank protection and navigation point of view. Consequently, all previous results are questionable for their general application under such conditions. Furthermore, the effect of the structures on successive bends as well as the interaction between the consecutive bends is also 


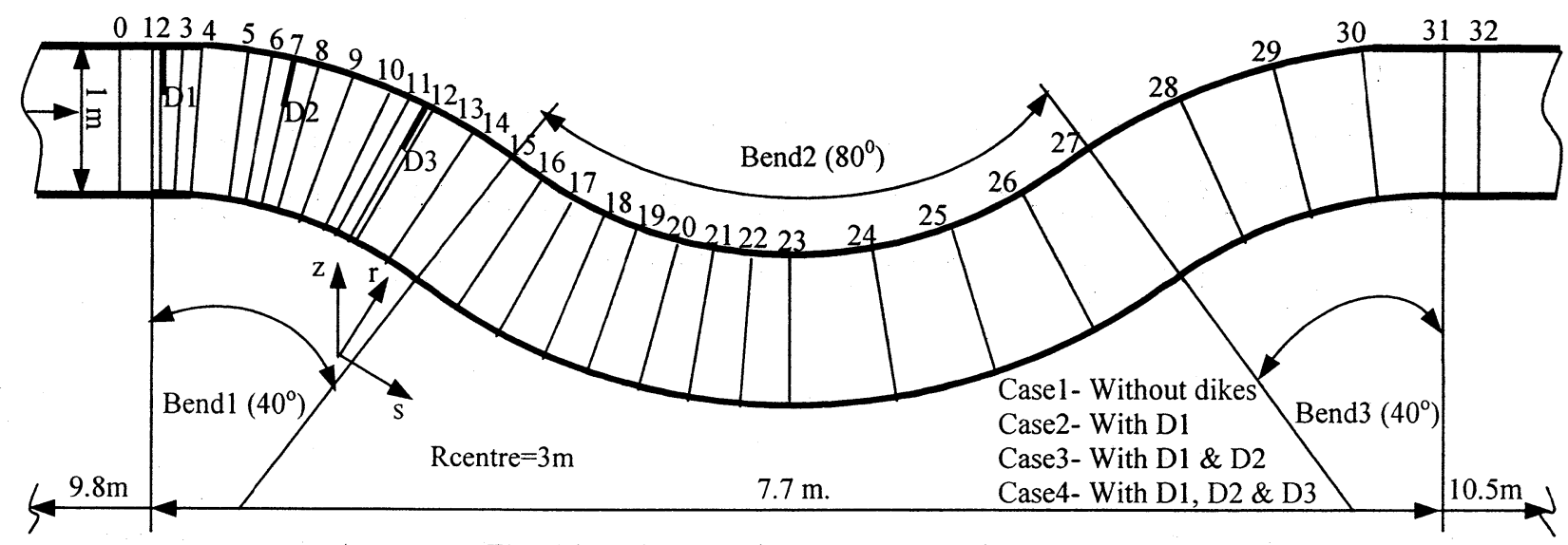

Fig.1 Flume layout and measurement sections

subject of interest from the design point of view. It is of importance to have an insight into the flow characteristics in order to gain better understanding of two-phase motion \& their interaction.

This study can be characterized as explorative with empirical approach. The objective of this study is to achieve an initial insight into the flow structure in bends, influenced by river training structures, not only locally but also in further downstream. Most of the past studies on bend flow concerned to the fully developed bend flow ${ }^{9}$. Some researchers have considered the convective acceleration due to the variable channel curvature ${ }^{10), 11)}$. However, in the presence of the structures in bend it may be of any feature as structure may act as a catalyst in such process. One of the topical interests of this study is to assess the effect of the change of bend direction on flow characteristics which is obviously not characteristic feature for developed meandering channel without training structures. It is thought that all these factors have been overlooked in previous studies and thus suggest itself for the detail analysis of the flow field throughout a meandering reach of the channel with \& without river training structures. Similarly, the study on flow field near the vicinity of each structure, in shear-layer and recirculation region is of quite significance as they are associated with sediment entrainment and deposition.

In this study, thorough measurement of stream wise and transverse velocity profiles was performed throughout the bend reach for all cases. The down flow velocity near the structure was also measured. The recirculation region, shear-layer \& the flow skewness was observed using dye as well.

\section{EXPERIMENTAL CONFIGURATION}

This experiment was conducted in laboratory flume of Applied Hydrology Laboratory of Hokkaido University. A $28 \mathrm{~m}$ long and $1 \mathrm{~m}$ wide rectangle flume with a meandering reach of $7.7 \mathrm{~m}$ wave length with 3 consecutive bends of $40^{\circ}, 80^{\circ} \&$
Table 1: Flow condition

\begin{tabular}{|l|c|}
\hline Approach flow depth, d (cm) & 9.5 \\
\hline Froude number, Fr & 0.22 \\
\hline Reynolds number, Re & 19950 \\
\hline Average velocity, Uo (cm/sec) & 21 \\
\hline Channel slope $($ Slope of platform) & $1: 2500$ \\
\hline Shear velocity, U* $(\mathrm{cm} / \mathrm{sec})$ & 1.9 \\
\hline
\end{tabular}

$40^{\circ}$ arc angles respectively (Fig.1) was constructed on a $28 \mathrm{~m}$ long and $2.5 \mathrm{~m}$ wide platform mounted on 4 pairs of synchronized screws with electrical motor slope regulation mechanism. The bed and walls are practically smooth. The upstream and downstream reaches were of $9.8 \mathrm{~m}$ and $10.5 \mathrm{~m}$ respectively, which are sufficient for turbulent flow to be fully developed as well as to avoid backwater effect of tailgate. The bend radius to channel width ratio, $\mathrm{R} / \mathrm{b}=3(\mathrm{R}=3 \mathrm{~m}, \mathrm{~b}=1 \mathrm{~m})$ has been adopted according to the most common curvature and bend migration ratio as reported by many researchers ${ }^{12)}$, 13). The width-depth ratio, about 10 , corresponds to the streams, where the channel migration is usually observed. In such meandering channel the bend flow does not properly developed due to small bend angle and magnitude. However, fully developed condition is not critical one for design purpose ${ }^{11}$.

The experimental condition has been adopted according to the characteristics of Plane Rivers with mild slope and sub-critical flow. Approach flow was kept nearly uniform. The experimental condition has been summarized in Table1. Non-submerged spur dikes were used in all cases $(\mathrm{h}=15 \mathrm{~cm})$. The length $-1 / 4$ of channel width $(25 \mathrm{~cm})$ and spacing-3 times spur's length $(75 \mathrm{~cm})$ for spur dikes were decided as a most common design parameter based on previous experience, however a conclusion has been drawn in this regard. Experiment was conducted for four cases: Case1: without spur dikes; Case2: one spur dike was placed at the radial distance of $1^{0}$ from the bend entrance (concave part); Case3: two spur dikes were placed at $1^{0}, 15^{0}$; Case 4 : three spur dikes were 
placed at $1^{\circ}, 15^{\circ}$ and $29^{\circ}$ respectively. The flow condition was same for all cases. Physical model was adopted as "Froudian model". The Reynolds number was relaxed. The approach Reynolds number seems to be smaller than in natural rivers (in our case it was 19950, whereas in natural channels it may be more than 40000). Nonetheless, flow around structures provides "auto-model" even in low approach Reynolds number ${ }^{14}$. The physical model has been attempted to perform experiment without distortion so as to get minimum scale effect and, in turn, similar feature of the flow kinematics. Velocity measurement was performed using a 3D Acoustic Doppler Velocimeter with the frequency of $25 \mathrm{~Hz}$ (25 samples/sec) for more than 30 second at each measurement points and obtained time averaged value. The velocity was measured in the radial and tangential directions in 8 to 12 points radially and 7-8 points over the depth for each measurement section. Besides, the vertical component of the velocity was also measured near the spur dikes, where it was more pronounced. The velocity measurement was concentrated on near bed region due to its concernment for sediment entrainment from the channel bed. The measurement sections were selected radially at every $2.5^{\circ}$ to $10^{\circ}$ depending on experimental case. The measurement sections have been numbered as shown in Fig.1.

\section{RESULTS AND DATA ANALYSIS}

All experimental results have been illustrated graphically in non-dimensional form in order to achieve quantitative notion. In this paper, some selected results have only been depicted. Data comparison for all four cases has been illustrated for the first half of the bend reaches due to their likeness for subsequent part.

\section{(1) Streamwise velocity profiles}

The streamwise velocity profile over the depth has been plotted for 3 points in Section1 (Case1) as a typical example as shown in Fig.2 (a). Most of the velocity profiles for the flow away from vicinity of dikes and back-flow region seem to be laid on exponential trendline indicating logarithmic distribution. However only few near-bed values followed Prandtl's log-law, which is normalized with depth average velocity, can be expressed as

$$
\frac{U_{s}-U_{m}}{U^{*}}=\frac{1}{k}\left(1+2.3 \log \frac{Z}{d}\right)
$$

where, $U_{s}$ - streamwise point velocity; $U_{m}$-depth average velocity; $U^{*}$-shear velocity; $k$-Karman constant; Z-vertical coordinate, $\mathrm{d}$-flow depth.
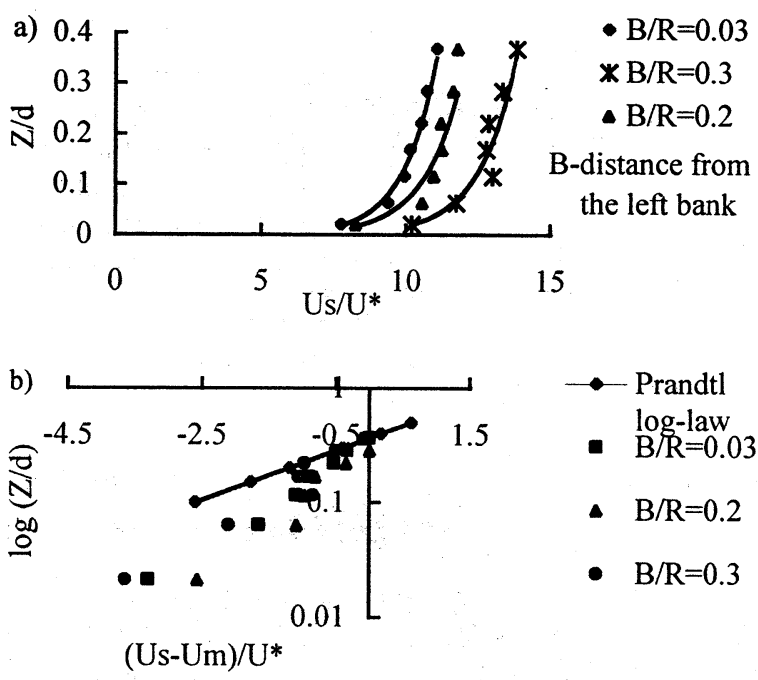

Fig.2 Near-bed streamwise velocity profiles (Case1: Sec.1)

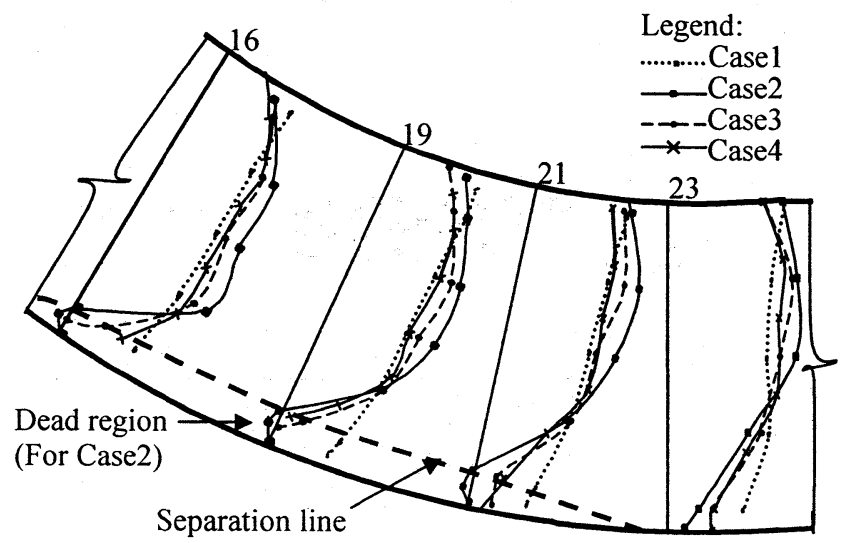

Fig.3 Streamwise velocity profile in the part of Bend $2(\mathrm{Z} / \mathrm{d}=0.3)$

Result has been illustrated in Fig.2 (b). The streamwise velocity profiles along the width in some sections of the first half of the Bend 2 have been depicted for all four cases in Fig.3. In this figure, the existence of a dead region can be seen along the outer bank of the first half of the Bend2. This region was most pronounced in Case2, which can be seen from Fig.4 (d) as well. While in Case1, streamwise velocity in this region substantially increased. For the sake of comparability, variation of streamwise velocity in all four cases along the left bank, right bank, central part as well as along the tip of the dikes has been illustrated in Fig.4.The velocity profile in case of without dike has shown the higher magnitude towards convex part of the bank. As the channel curvature changed its direction, the velocity tended to become higher again in convex bank, which can be seen from Fig.4 (a). This evidence shows contradiction in terms with movable bed condition. Nonetheless, this fact was elucidated by some theoretical and experimental studies on flow with vanished transverse bed slope in a curved channel ${ }^{15), 16), 17)}$. In Case $3 \& 4$, near the vicinity of second spur dike, a strong back flow was 

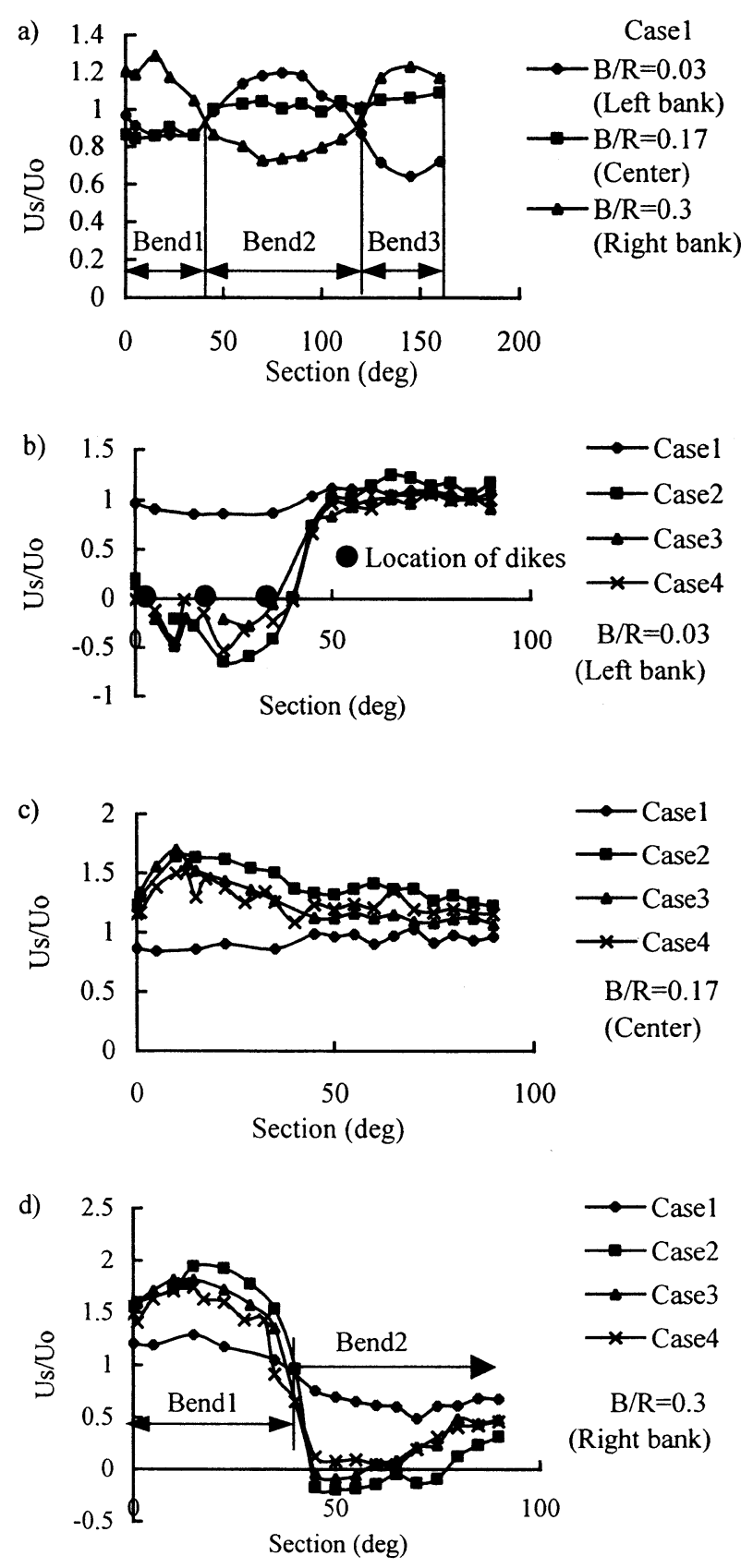

(Right bank)

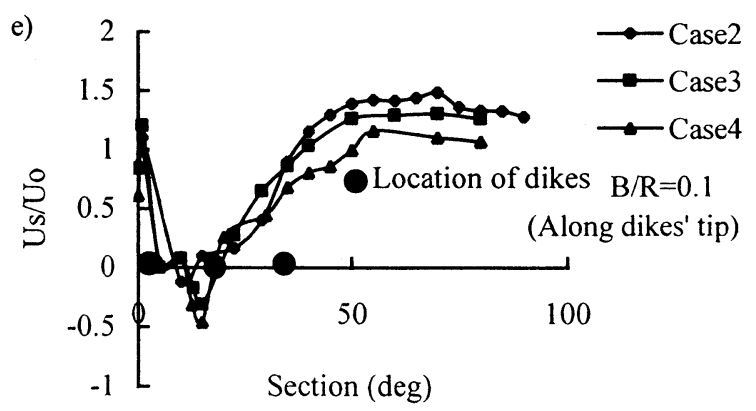

Fig.4 Variation of streamwise velocity along the bend reach of channel $(\mathrm{Z} / \mathrm{d}=0.38)$

observed that can be seen from Fig.4 (e). Variation of downstream velocity along dikes' tip appears to be similar for all three cases with dikes except near dike $1 \& 2$. Streamwise velocity profile along shear -
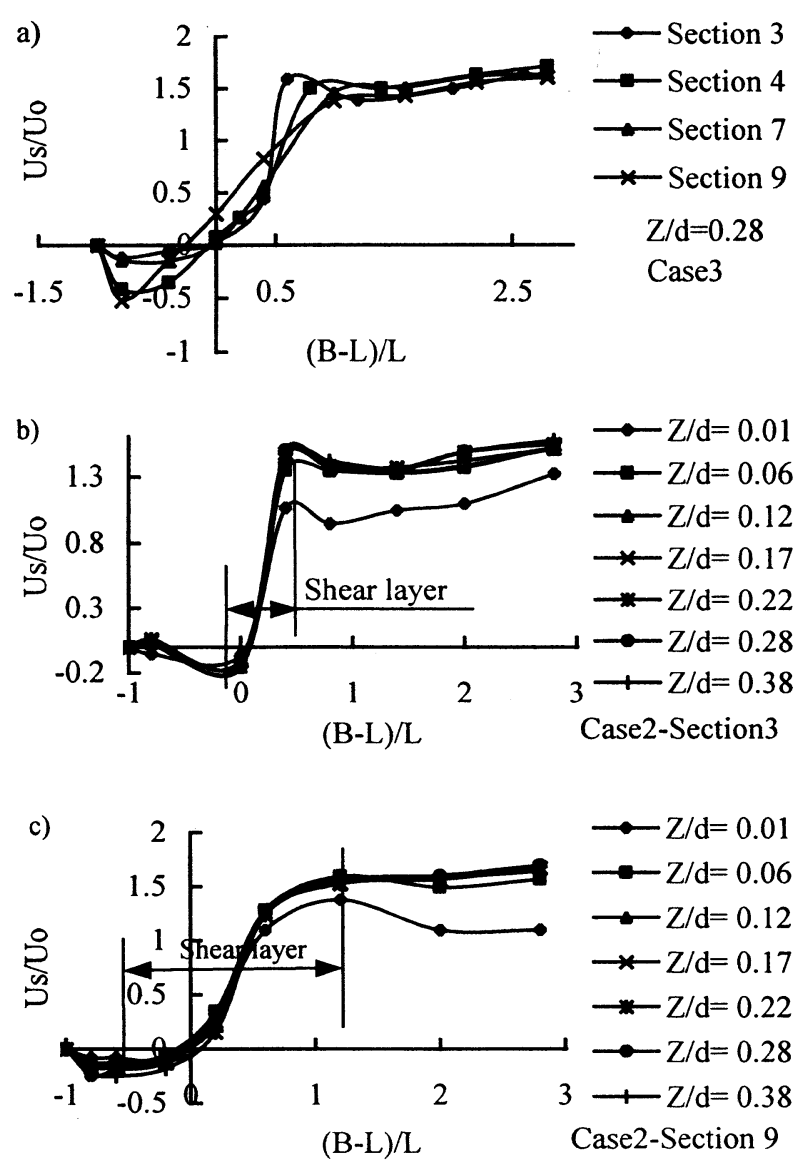

Fig.5 Streamwise velocity profile along shear layer

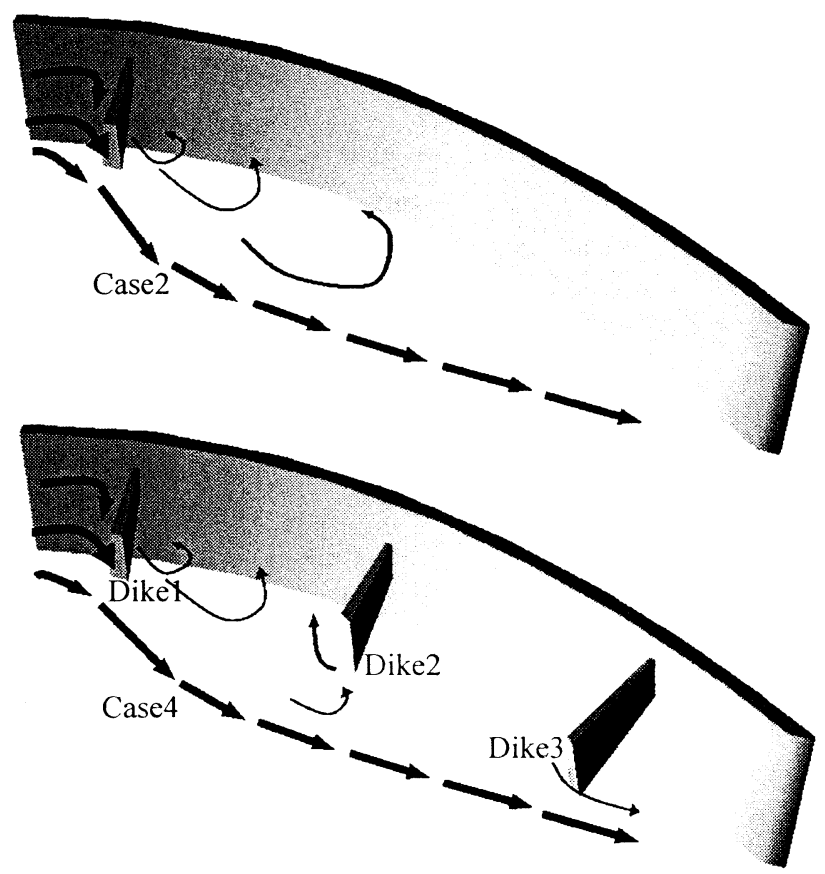

Fig.6 Schematic sketch of flow patterns.

layer in some selected sections has been depicted in Fig.5. The schematic sketches of flow deflection are depicted for Case 2 and Case 4 in Fig.6, which shows the down flow \& deflection near dike1, back flow near dike $2 \&$ no deflection near dike 3 in Case 4. 

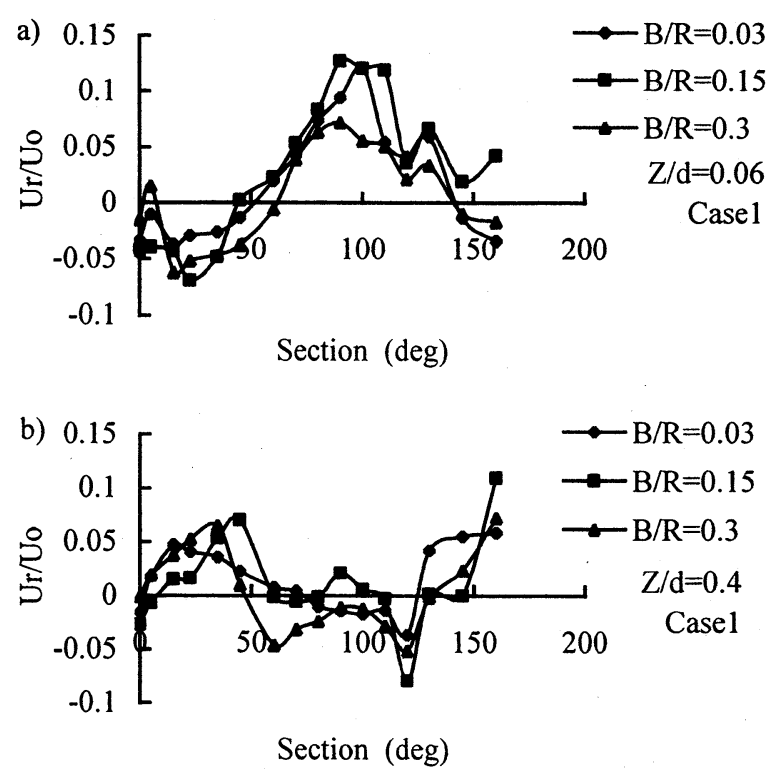

Fig.7 Variation of transverse velocity along the channel.

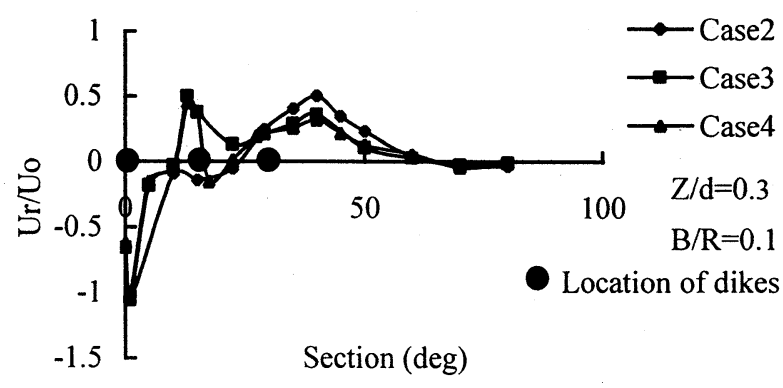

Fig.8 Variation of transverse velocity along tip of dikes

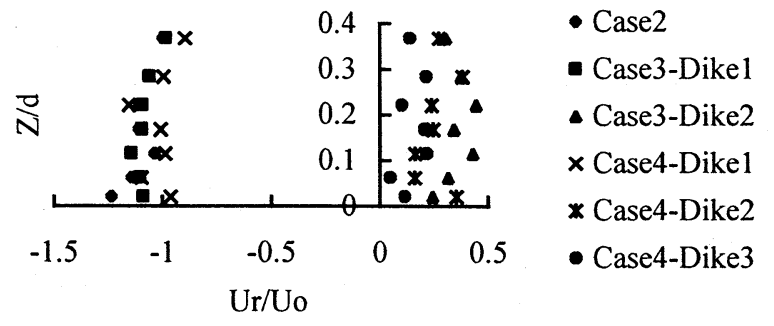

Fig.9 Cross-flow velocity profiles near tip of dikes

The effect of the channel constriction on the opposite bank can be assessed from Fig.4 (d). In all cases, maximum velocity was observed in section after $10^{\circ}$ to $15^{\circ}$ from the location of first dike, which can be defined as maximum constricted section. As depicted in Fig.5, length of shear layer was found to be smaller near the constriction with high velocity gradient and larger in successive sections with low velocity gradient. Moreover, they are similar over the depth that can be seen from these figures (The velocity was normalized with average velocity and width with constriction ratio). In constricted region, increment of velocity was observed near the right bank as well. It is significant to note that the small eddies having high energy were observed to be originated from the tip of the first dike spreading throughout the shear-layer region. Moreover, they were seen to have traveled far downstream. Such eddies may be the supplementary cause of scour holes. The length-width ratio of recirculation region was found to be about 6 in Case $2 \& 3$ and slightly greater in Case4. The reattachment point was observed to be located near the beginning of the second bend. Similarly, critical distance was found to be about 5 times dike's length. Critical distance is defined as the distance between the tip of the first dike and the point at separation line where it's width becomes equal to the dike's length. These evidences were confirmed with dye observation as well.

\section{(2) Transverse velocity profiles}

In this experiment, the maximum transverse velocity (Ur) near the bed was found to be about $10 \%-13 \%$ of average velocity for the case of without structure. Variation of near-bed transverse velocity along the channel for couple of flow depths in Case1 has been illustrated in Fig.7 (a) \& (b). These figures show that the skewness has become more pronounced near the bed and changed its direction along of changing channel bends as well as in upper layer. Presence of the river training structures significantly produced secondary current as well as down flow velocity component near the tip of the structure. Flow characteristics near each spur dike were found to be distinctive, which can be seen from Fig.8 and Fig.9. According to Fig. 9, the maximum deflection occurred around first spur dike in all cases. Near dike2 and dike3 deflection did not occur. In addition, a strong down flow was observed near the bed, particularly at the tip of the first dike in all cases. The magnitude of these vertical velocity components was observed within the range of $30 \%$ to $40 \%$ of the average approach velocity. Near the tip of other dikes, absence of down flow was found.

\section{SUMMARY AND DISCUSSION}

This experimental result has corroborated some past studies as well as appends some additional information to them. In case of without structures, the flow pattern that was found in this experiment is thought to be typical one for mildly meandering channel with short bends \& low magnitude. In this case, it can be seen from our results that flow accelerates or decelerates gradually near the both bank according as changeable bend direction \& nearly uniform along the center. One important observation in our experiment is the fact of the presence of a dead region throughout the outer part of second bend, which seems to be influenced considerably by the allocation of training structures 
in preceding bend. This implies that these structures produce effect not only in nearby region but also in further downstream and such effect is seen to have been influenced by channel configuration. It can be concluded that flow pattern \& in turn bed topography with training structures in a mildly meandering channel may have distinctive feature than those of in straight channel \& even in strong bend. The structures placed in one bend may exert substantial influence on flow pattern in subsequent bend having different mass and momentum exchange depending on channel configuration as well. On the other hand, bed variation near these structures may significantly depend on the flow field around them, viz. down-flow, vortexes etc. Another noteworthy evidence concerns to the distinctive features of the flow field around each structure, which is obviously influenced by their allocation, in particular, whether subsequent structures have their individual influence on flow or not, in other words, their spacing is more than critical distance as well as recirculation region or not. In our experiment, the distance between first and second dike was kept less than critical while third dike was placed slightly further but within the recirculation region induced by the first dike. So, no significant effect on flow field, caused by second \& third spur dikes, was observed. In this experiment, the length-width ratio of recirculation region was found to be less than those observed in cases of straight channel. This may be due to the channel curvature as well. It was noted that the maximum constricted velocity occurred in Case2, at the same time a dead region in successive bend was seen to have most pronounced in the same case. As observed in this experiment, constriction ratio is also one of the important factors which may be responsible for sediment entrainment not only from vicinity of dike but from the region near opposite bank as well.

Consideration of the channel plan-form as well as influence of the structure in further downstream appears to be of great importance, which was apparently overlooked in earlier developed design criteria for river training work. Results of this experiment indicate the necessity of more rational approach as well as more efficient and economical design criteria, viz. varying the construction volume of structure according to their allocation, simultaneous use of different types of protection techniques etc. It is thought that this experimental evidence might provide an initial insight into the flow behavior not only around structures but also in successive downstream region, which would be of importance for the better understanding of the interrelation between the flow and sediment transportation in a mildly meandering channel with training structures.

Apart from all, this experimental data can serve as a benchmark for numerical study. Obviously, this study should be followed by movable bed experiment in terms of more wide range of all variables for its ultimate verification so as to develop an improved approach for river training technique in consideration of their impact on function of entire river regime.

\section{REFERENCES}

1) Rajaratnam \& Nwachukwu: Flow near groin-like structures, ASCE, Journal of Hydraulic Engineering, Vol.109, No.3, 1983.

2) Garde et al.: Study of scour around spur dikes, ASCE, HY 6, Vol.87, 1961.

3) Kothyari \& Rangaraju: Scour around spur dikes \& bridge abutments, IAHR, Vol.39, N0.4, 2001.

4) Fukuoka et al.: Design of bed variation control measures at OjiyaKoshiji in the Shinano river, Journal of hydraulic, Coastal \& Environmental Engineering, No.698/II-58

5) Tominaga \& Ijima: Effects of interval length on flow structures around submerged spur dikes, Annual Journal of Hydraulic Engineering, JSCE, Vol.46, 2002 (in Japanese).

6) Chen \& Ikeda: Horizontal separation flow in shallow open channel with spur dikes, Journal of Hydroscience \& Hydraulic Engineering, Vol.15, No.2, 1997.

7) Uijttewaal et al.: Exchange processes between a river \& its groyne fields: Model experiment, ASCE, Journal of Hydraulic Engineering, Vol.127, No.11, 2001.

8) Muneta N. \& Shimizu Y.: Study of flow around spur dikes, International conference on ESWRU, Bangkok, 1993.

9) Kikkawa et al:: Flow and topography in curved open channel, ASCE, Journal of Hydraulic Engineering, Vol.102, No.HY9, 1976.

10) Yalin M.S.: River Mechanics, Pergamon Press Ltd, 1992.

11) Odgaard \& Bergs: Flow processes in a curved alluvial channel, Water Resources Research, Vol.24, No.1, 1988.

12) Leopold \& Wolman: River meanders, Bulletin of the Geological Society of America, 71, 1960.

13) Begin Z.B.: Curvature ratio and rate of river bend migration-update, ASCE, Journal of Hydraulic Engineering, Vol.112, No.10, 1986.

14) Mikhalyov M.A.: Theory of similarity \& dimensional analysis (in Russian), Izd. SPBGTU, St.Petersburg, 2001.

15) Johannesson \& Parker: Velocity redistribution in meandering rivers, ASCE, Vol.115, No.8, 1989.

16) Rozovskii I.L.: Flow of water in bends of open channel (in Russian), Izd. AN USSR, 1957.

17) Tamai \& Ikeuchi: Longitudinal and transverse variation of the depth -averaged flow fields in a meandering channel, Journal of Hydroscience \& Hydraulics, Vol.2, No.2, 1984.

(Received September 30, 2002) 